\title{
LA E DE DELFOS
}

\author{
NeUS CALVO ESCAMiLla \\ IES Marcos Zaragoza Villajoyosa (Alicante)
}

Recibido: 26/7/2012

Aceptado 08/10/2012

\section{Resumen}

Los hallazgos arqueológicos nos ayudan a hacer una interpretación de la historia que se oculta detrás de los mitos, en concreto me centro en los referidos a la historia del oráculo de Delfos y Dodona. En los tiempos finales del culto de Delfos, estuvo Plutarco como sacerdote del mismo, y en sus Diálogos Píticos nos proporciona valiosa información sobre el mismo. Pero hay un tema curioso que no acaba de resolver, a pesar de sus interpretaciones o exégesis: el significado de la E de Delfos. Mi propuesta es una interpretación que conecta directamente con la más antigua dueña del Oráculo: la Gran Diosa Gea, y que en tiempos de Plutarco -ni después- fueron capaces de reconocer.

Palabras clave: Delfos, Dodona, Tifón, Apolo, Gea, Zeus, Dione, Atenea Pronaia, Delfine, Disco de Festos, Minoico, Plutarco, exégesis, peine, misoginia, androcentrismo.

\begin{abstract}
Archaeological findings help us to make an interpretation of history that is hidden behind the myths; I focus in particular those relating to the history of the oracle at Delphi and Dodona. In last times, the cult of Delphi, when Plutarch was a priest of the same, in his Pythian Dialogues provides valuable information on it. But there is a curious topic that he doesn't completly resolve, despite his exegesis: the meaning of the E at Delphi. My proposal is an interpretation that connects directly to the oldest owner of Oracle: the Great Goddess Gaia, and that point in times of Plutarch, or even later, were not able to recognize.
\end{abstract}

Key words: Delphi, Dodona, Typhon, Apollo, Gaia, Zeus, Dione, Athena Pronaia, Delfine, Phaistos Disc, Minoan, Plutarch, exegesis, comb, misogyny, adrocentrism. 



\author{
Terpsícore me dijo \\ viejos cuentos amorosos para cantar \\ al vestido blanco de las mujeres de Tanagra \\ $y$ de la gran ciudad encantada \\ en mi voz, clara como una golondrina. \\ Corina, fr.1(PMG 655), siglo V a.C.
}

Siempre me ha gustado observar el vuelo de las golondrinas. Cuando estaba embarazada de mi hija, me pasaba horas estudiando delante de una ventana, y ellas me llenaban de alegría y vitalidad. Incansables suben, bajan, se cruzan, se persiguen...Y me encanta oír sus gorgojeos cuando, paradas sobre el cable de la luz, parlotean como comadres en una esquina. ¡Quién pudiera entender su idioma para enterarse de tanto cotilleo!

El canto de la abubilla me trasporta a un espacio atemporal y su vuelo atravesando el cielo en mi camino, me conecta al latido de un corazón que late para todos igual. Las garcetas blancas alzando el vuelo son un mensaje de tranquilidad con su vuelo ancho y pausado. Durante el tiempo de espera de mi hijo, la aparición del pequeño petirrojo me hacía sonreír pensando en él, e imaginándolo feliz y juguetón como aquel pajarillo.

Estudié filología clásica porque me atraían los mundos antiguos, los secretos ocultos que aquellas lenguas indescifrables parecían poder desvelar. Su estudio fue descubriéndome una realidad que no siempre me gustó. El mayor peso de la cultura que se nos transmitía recaía sobre cuestiones bélicas: enfrentamientos de poder, grandes reyes, emperadores, generales, grandes batallas, victorias y derrotas militares.

Nadie hablaba de golondrinas y de garzas.

Acabé la carrera y ya hace años que enseño a mis alumnos a traducir los comentarios de las horribles hazañas bélicas de César.

En cambio la mitología me abrió una puerta maravillosa. Al principio buceaba en un mar de confusión, mitos con múltiples versiones, diosas y dioses griegos y romanos con el mismo nombre, con nombre distinto, sincretismos, asimilaciones con mitología egipcia y oriental... Poco a poco, fui leyendo entre líneas de tanta confusión el proceso aglutinador que la mitología había realizado a lo largo de siglos de relatos orales y populares, algunos convertidos 
en versiones más «oficiales» al ser recogidas en los Himnos homéricos o en la Teogonía de Hesíodo. Fui comprendiendo, con ayuda de las y los estudiosos de los mitos, el valor simbólico de estos relatos, a veces incomprensible a primera vista. Me impactaba el horrible papel de Zeus, el famoso padre de los dioses, que se dedicaba a violar mujeres y diosas por todas partes. Más tarde descubrí con el feminismo la llamada cultura patriarcal en la que vivimos, que hunde sus raíces en esta cultura de la violencia que revela la figura de Zeus. Y empecé a preguntarme ¿y dónde están las mujeres escritoras, pensadoras, científicas que nos han precedido? Durante la carrera sólo llegué a tener noticia de la poeta griega Safo y de una escritora de latín medieval llamada Egeria. Más tarde, por mi cuenta, fui conociendo la existencia de Diótima, de Hipatia, de Aspasia, de Corina y muchas más que todavía hoy sigo descubriendo, admirada del silencio en el que hasta ahora estaban. En la mayoría de los casos han sido recuperadas gracias al trabajo de otras mujeres, y por primera vez he podido ver algunos de sus nombres en los libros de texto que se trabajan en las aulas.

Y un día, como si fuera un regalo llegado desde aquellos remotos tiempos de mitos y lenguas muertas, descubrí unas pinturas que me emocionaron profundamente: las golondrinas de los frescos minoicos. Son las mismas que tanta alegría me transmiten ahora a mí. De repente me sentí muy cerca de aquellas personas que vivieron hace ya más de 3.000 años: no éramos tan distintos. Estas pinturas pertenecen a la civilización prehelénica, a la cultura que existía antes de las invasiones de los pueblos del norte que trajeron la lengua griega. Como han visto algunos historiadores, el mito del Minotauro representaría esta hegemonía de Creta sobre Atenas (la cual debe pagar tributo a Minos) y el cambio de poder (el rescate de Teseo de sus compatriotas atenienses y la recuperación del anillo de Minos del mar, como símbolo del poder monárquico que se traspasa a Atenas) ${ }^{1}$.

Esta forma de interpretar los mitos como explicación de la historia ya la practicaron en la antigüedad numerosos autores, desde Heródoto hasta el famoso Evémero, la exégesis. Los filósofos griegos la practicaron con frecuencia, ésta podía ser exégesis física (la que ve en los mitos realidades de orden físico), exégesis histórica (ven personajes y hechos históricos pero deformados

1. El mito cuenta cómo Teseo, hijo del rey de Atenas, se ofrece voluntario para ir en el barco con los jóvenes que cada novilunio Atenas debe entregar como tributo a Creta. Allí consigue vencer al Minotauro en el laberinto y liberar a los suyos gracias a la ayuda de Ariadna, la hija de Minos, rey de Creta. En el camino de regreso abandona a Ariadna en una isla, y se lanza al mar para recuperar el anillo de Minos. 
por lo maravilloso), exégesis psicológica y moral, e incluso exégesis mística (símbolos de realidades espirituales más altas, cf. neoplatónicos).

Por lo tanto, los mitos no son sólo curiosos relatos antiguos con los que nos entretengamos, o que sirvan de inspiración a generaciones y generaciones de artistas y escritoras/-es para sus obras. Son testimonios tan valiosos y llenos de información como los hallazgos arqueológicos o las fuentes escritas.

Hace unos años preparando unos textos de griego para las clases, descubrí que las fábulas de Esopo se remontaban a una época tan remota como las civilizaciones de Mesopotamia, ya que se encontraban algunas narraciones idénticas en esta cultura y también en la India. A pesar de la fuerza deformadora de la transmisión oral, es fácil reconocer en ellas ese pasado común.

En el caso de la mitología la deformación de los mitos todavía es mayor: en una versión se habla de una divinidad como padre o madre, que en otra pasa a ser el marido o esposa, o tiene otro parentesco diferente, o se le atribuyen historias y descendencia diferentes. Pero siempre se puede reconstruir un hilo común, algo parecido a lo que ocurre a nivel de la evolución lingüística. Quizá más confuso porque no hay reglas que se puedan aplicar a esos cambios, y tampoco existen referencias temporales seguras. Pero muchas veces resulta bastante evidente, desde una visión retrospectiva, elaborar nuevas exégesis que complementan los datos ya conocidos.

Ya hay mucho escrito en este aspecto, yo me voy a dedicar a un tema muy concreto: los mitos y su exégesis en torno al conocido santuario de Delfos. La interpretación es siempre algo subjetivo y dependerá de la forma de mirar del sujeto que la realiza. Lamentablemente, hasta ahora hay una gran carencia de sujetos femeninos en dichas interpretaciones alegóricas. Quizá mi interpretación sea errónea, no pretendo darle valor de verdad absoluta, sólo son conjeturas tal y como otros se han aventurado a realizar.

Mi punto de partida ha sido el Oráculo de Delfos. Siempre ha sido un lugar, una historia que no han dejado todavía de atraerme y de aportarme nuevos descubrimientos. Hace algunos años tuve la suerte de viajar a Ioanina con $\mathrm{M}^{\mathrm{a}}$ José, amiga y compañera de trabajo. En el trayecto a esta ciudad situada en el Épiro, tuvimos ocasión de pasar un día en Delfos. Fue muy emocionante ver el monte Parnaso (el hogar de las Musas), las rocas Faedriadas ${ }^{2}$, la fuente Castalia, y el hermosísimo templo circular del santuario de Atenea Pronaia. Es un paisaje montañoso y de vegetación típica mediterránea, muy parecido al que me rodea en el lugar que habito en la provincia de Alicante. Esto me hizo

2. El nombre de las rocas también hace referencia a divinidades femeninas, así como las Hamadríadas son las ninfas que viven unidas a un árbol, el nombre de las rocas está formado por la misma raíz -dríadas.a, luego sustituida por Apolo, aos interpreten. 
sentir aún más cerca de aquel mundo misterioso y mítico que debió existir allí hace varios miles de años.

Delfos era considerado el centro del mundo, según narra el mito en el que Zeus soltó dos águilas que rodearan la tierra, y allí donde se juntaran sería el centro del mundo. Y en este «ombligo» de la tierra es donde existen unas condiciones idóneas para el contacto con el mundo subterráneo, las entrañas de donde brotan las respuestas proféticas. Según el escritor griego Pausanias existió una grieta de la cual emergían vapores que conferían esta capacidad adivinatoria, pero su testimonio es muy tardío (siglo II d.C) y lo cierto es que nunca se encontraron restos de dicha fisura. Versiones más antiguas atribuyen esta cualidad a las aguas del lugar, tanto a la fuente Castalia como a la que cuentan que hubo dentro mismo de la cella donde se encontraba la Pitia ${ }^{3}$.

Pero me interesa más analizar de quién provenía dicha inspiración, que la cuestión de que fueran vapores, agua, o incienso de laurel y harina los que ayudaban a las sacerdotisas en sus trances. Porque es en este punto donde la historia, el mito y la arqueología se unen para dar testimonio de la transformación cultural que se produjo en aquel mundo desde el neolítico a la época greco-romana, tiempo que abarca la existencia del santuario.

El primer asentamiento en la zona de Delfos se produjo en el neolítico (4.000 a.C.) en la cueva del Parnaso llamada Korykeias Andron ${ }^{4}$, pero en el emplazamiento del santuario los primeros restos arqueológicos pertenecen a la edad del bronce tardío, en la que hubo un asentamiento micénico. Y la mayor actividad se registra a partir del siglo VIII a.C. ${ }^{5}$, cuando se construyó el doble santuario de Apolo y Atenea Pronaia. Siempre se habla de Delfos como el santuario de Apolo, y se suele ignorar la presencia de Atenea, a la que pertenece -en mi modesta opinión- uno de los templos más hermosos y representativos de Delfos: el Tholos circular. La parte del santuario de Apolo es muy extensa, ocupando varias terrazas en la ladera de la montaña, en cambio el

3. Se refieren a la fuente Cassotis, localizada fuera del templo de Apolo, muy cerca de su entrada, y que muy bien pudo estar canalizada hasta dentro del templo. En el recinto del santuario se hallan identificados restos de otras fuentes, hoy en día ya secas.

4. «Andrón» significa «habitación de los hombres», así como existe la forma «gineceo» para la de las mujeres, pero la forma «Korykeias» hace referencia a «doncella», también atribuida al nombre de una ninfa llamada Koryké. En el diccionario A. Bally aparece el adverbio «korikós», significando «como una joven hija». Así pues, resulta curioso este cruce entre un sustantivo que determina la casa de los hombres con el adjetivo que la califica como femenina. El nombre y la descripción de la cueva ya aparece atestiguado en Pausanias, entre otros escritores antiguos.

5. Delfos <http://odysseus.culture.gr/h/3/gh351.jsp?obj_id=2507>, consultado el 18-07-2012. 
asentamiento del santuario de Atenea -donde se halla el Tholos- es un verdadero locus amoenus. Está situado a la izquierda de la carretera que viene desde Atenas, un poco antes de la curva en la que se encuentra la fuente Castalia. Es decir, que era el paso obligado de los consultantes-peregrinos antes de llegar al magno complejo religioso de Apolo, de ahí que algunos interpreten «Pronaia», como pro- (antes), y -naos (templo) ${ }^{6}$. Las excavaciones han demostrado el uso de este lugar como santuario desde época micénica, dedicado a una deidad femenina precursora de Atenea según lo atestiguan las pequeñas estatuillas femeninas de terracota. Además del Tholos, que es de época más tardía, existieron otros templos en el recinto dedicados a Atenea, derribados por terremotos y desprendimientos de rocas de las propias Faedriadas, y luego vueltos a construir. El más antiguo de ellos fue construido en el siglo VII a. C., y debió ser de los más grandes de su época según nos informan los tambores conservados de sus columnas ${ }^{7}$.

Nuestro viaje continuó hasta Ioannina, y allí descubrimos otro famosísimo oráculo: el santuario de Dodona, considerado el más antiguo de toda Grecia ${ }^{8}$. Este oráculo también lo preside un dios masculino: Zeus. Esa es la primera información que recibimos, pero en cuanto se escarba un poquito, sorpresa: también estuvo dedicado a dos divinindades: Zeus y Dione. Mi profesor de griego moderno, Spirou, nos indicó que el nombre de Dodona, provenía precisamente de una forma muy antigua que bien podría descifrarse como «Dios-Dione» ( ${ }^{*}$ Dy-F-os-Dy-F-o-ne $\left.>\Delta \omega \delta \omega ́ v \eta\right)^{9}$. Y también es curiosa coincidencia el hecho de que la elección del lugar se deba a las aves: dos palomas que parten de Tebas, una vuela hasta Libia, donde pide que se establezca el culto a Amón (el equivalente de Zeus en Egipto), y la otra vuela a Dodona. Allí se posa sobre una encina (o haya, según Heródoto) y pide con voz humana que se dedique dicho árbol a la transmisión de la voluntad del dios (y de la diosa, digo yo $)^{10}$.

6. Aunque también podríamos atribuir este epíteto a la forma compuesta por naias (valas), nominativo de Náyade, derivado del adjetivo náios,-a,-on que significa «marino/-a»; y que adquiere más sentido si consideramos que los más antiguos testimonios de culto del lugar, también se remontan a Poseidón o una divinidad marina, luego sustituida por Apolo, al cual,a su vez, también se le representa como un delfín.

7. mapa de Delfos <http://goo.gl/maps/4sEQ>

8. Dodona< http://odysseus.culture.gr/h/3/eh351.jsp?obj_id=2365> consultado 18-07-12

9. No he tenido ocasión de profundizar en dicha etimología, pero tratándose de una toponimia tan antigua, podría ser el tratamiento fonético del dialecto dórico o incluso del sustrato previo a la aparición de las formas griegas.

10. Heródoto hace la siguiente interpretación: «Pienso que los dodoneos llamaron a las mujeres palomas porque eran bárbaras, y se les figuraba que hablaban a semejanza de aves. Dicen que con el tiempo la paloma habló con voz humana, esto es, cuando la 
En el caso de Dodona las sacerdotisas y sacerdotes interpretaban el sonido de las hojas del roble al ser movidas por el viento y las aves que anidaban en él, y se ayudaban de calderos dispuestos en trípodes alrededor del árbol. Cuentan que iban descalzos y dormían sobre el suelo para mantener el contacto con la tierra, de la cual provenía la inspiración profética, así como de una corriente de agua que por allí transcurría.

Además de Dione también se rindió culto a Afrodita y a Temis, asociándolas a la misma «casa»y «templo» que Zeus. De nuevo el flagrante androcentrismo de los que transmiten la historia: se reconoce abiertamente que en su origen el santuario se dedicó a una deidad femenina relacionada con la tierra y la fertilidad, se sabe que posteriormente el oráculo fue compartido por Zeus y Dione, y luego incluso por dos diosas más, sin embargo, la primera $-\mathrm{y}$ a veces única- forma de nombrar el oráculo de Dodona, es como el oráculo de Zeus.

Pero veamos qué nos cuenta el mito sobre el oráculo de Delfos. En los Himnos homéricos se recoge la leyenda de que en este lugar ya existía un oráculo de la diosa Gea, custodiado por la serpiente o dragón Pitón. Apolo, siendo un niño de varios días, dejó Delos, donde había nacido, y marchó en busca de un lugar apropiado para levantar su templo. Al llegar al Parnaso le gustó, y decidió establecerse allí, pero para ello tuvo que matar con sus flechas a la serpiente Pitón. Luego se exilió al monte Olimpo para purificar su crimen. Dicen que los primeros sacerdotes del nuevo oráculo de Apolo fueron unos comerciantes cretenses de Cnosos que milagrosamente fueron desviados de su ruta hasta Krisa, el puerto cercano a Delfos. El culto a Gea no desapareció por completo, un pequeño lugar fue dejado para ella en donde estuvo su oráculo, de forma que pudiera seguir siendo venerada la antigua dueña del lugar. Se considera a Apolo un dios pacífico y mediador, y el santuario se convirtió en centro de actividad política, donde se reunía la Anfictionía. Las consultas eran tanto de tipo personal como político.

Y ¿qué nos cuentan los mitos de Pitón? Dicen que era el dragón encargado por Gea de cuidar de su hijo Tifón. Otras versiones hacen a Tifón hijo de Crono y Hera, otras sólo de Hera. En lo que coinciden es en el enfrentamiento de Tifón con Zeus y todos los olímpicos, lucha en la que en un primer momento llegó a vencer Tifón y todos los dioses se tuvieron que refugiar en Egipto. Tifón enterró los tendones de Zeus y se los dio a custodiar a la dragona Delfine. Posteriormente Hermes y Pan (o Cadmo) recuperaron los tendones de Zeus y

mujer les decía cosas inteligibles; mientras hablaba en lengua bárbara les parecía proferir voces a la manera de ave, pues ¿de qué modo una paloma podría hablar con voz humana? Al decir que la paloma era negra, indican que la mujer era egipcia.» (Hdto. 2,57) 
éste pudo vencer a Tifón que yace enterrado bajo el volcán Etna. Es llamativa la descripción que el mito hace de Tifón:

Tifón era un ser intermedio entre un hombre y una fiera. Por la talla y la fuerza superaba a todos los restantes hijos de la Tierra; era mayor que las montañas, y a menudo su cabeza tocaba el cielo. Cuando extendía los brazos, una de las manos llegaba a oriente, y la otra, a occidente, y en vez de dedos tenía cien cabezas de dragón. De cintura para abajo estaba rodeado de víboras. Tenía el cuerpo alado, y sus ojos despedían llamas ${ }^{11}$.

En esta descripción podríamos ver una alegoría que explica la extensión de un culto diferente al culto a los dioses olímpicos, una religión en la que se veneraba a las serpientes. No tiene mucho sentido que Pitón protegiera a Tifón, cuando el propio Tifón parece tener una fuerza y un poder inmenso. Por lo tanto, estas incoherencias del mito son causa de la superposición de distintas fases por las que pasaría esta cultura religiosa que parece extenderse desde el Mediterráneo a la India. Basta mirar el panteón hindú para encontrar claras referencias a estas divinidades, rodeadas de serpientes y cobras, y que también aparecían en la cultura minoica representadas por la diosa o sacerdotisa de las serpientes.

Otro cruce de mitos lo encontramos en Delfine. Según el diccionario de Mitología, existen dos dragonas así llamadas: una sería la ya apuntada antes, encargada de la vigilancia de los tendones de Zeus, de la cual se dice que era medio mujer, medio serpiente; otra sería una Delfine más antigua, que guardaba la fuente de Delfos antes de que existiera la serpiente Pitón.

Todas esta versiones del mito apuntan al culto a una divinidad «Serpiente», ya sea en su faceta femenina (Delfine) o masculina (Pitón y Tifón), muy unida a un culto a la tierra (Gea). Y todas las luchas referidas en el mito, representan la transición entre esta religión más antigua y la nueva que introduce el culto a las divinidades olímpicas con el nuevo orden impuesto por Zeus: el patriarcado. Mercedes Madrid en su tesis sobre la misoginia griega, cuando analiza los poemas de Hesíodo, lo explica claramente:

Lo que hay, sin embargo, en la Teogonía es un traspaso de las cualidades de Gea a Zeus, que, a su vez, provoca un cambio en la valoración del principio masculino (representado por Urano, Crono y Zeus) y del femenino (encarnado en Gea, que actúa ayudando, o sirviéndose de Crono, Rea y Tifón) a lo largo del mito de sucesión de los Uranidas ${ }^{12}$.

11. Grimal, Pierre, Diccionario de Mitología griega y romana ed. Paidós, 1986, p. 516.

12. MADRID, Mercedes. La misoginia en Grecia. Feminismos. Ed. Cátedra. U.de Valencia, 1999. 
Y refiriéndose tanto a la primera esposa de Zeus, Metis (la cual acaba devorando para apropiarse de sus cualidades) como de la segunda, Temis, que representa la justicia y la adivinación:

Se produce así una inversión en la caracterización de los principios masculino y femenino que deja del lado del primero, es decir de Zeus, el orden, la prudencia, la sabiduría astuta, la previsión del futuro y la capacidad de dar la vida, y, por oposición, de acuerdo con el principio de la polaridad, del lado femenino, la desmesura, el desorden y la imprudencia...

Así que, detrás de un relato que parecía una lucha del «bueno» de Zeus contra el «malvado» dragón, se vislumbra un cambio radical en la forma de ver el papel de la mujer en la sociedad. Para Hesíodo la mujer, «la raza de las mujeres», será «el gran mal». Y las divinidades femeninas sólo tienen un rol en este nuevo panteón, en tanto que estén subordinadas a Zeus. Son buenas las mujeres que paren hijos que se parecen a sus padres (mito de las Edades). Atenea, hija de Metis, ahora se convierte en la hija nacida de Zeus. Pero los restos de la antigua religión se traslucen a través de algunos de sus atributos: diosa con ojos de lechuza, escudo con la cabeza serpentina de Medusa, introductora del olivo. Es decir, la representación de la divinidad femenina por medio de aves, serpientes y árboles, la conexión con la Tierra que antes era detentada por Gea.

Estas exégesis o interpretaciones alegóricas de los mitos se apoyan también en hallazgos arqueológicos. Pero por muchos museos que he visitado en todos los viajes que he podido realizar a Grecia, la visión que me lleva a enlazar todos estos mitos con una religión anterior de características comunes, se la debo agradecer al colosal trabajo de la arqueóloga Marija Gimbutas. Ella publicó las imágenes de cientos de estatuillas y objetos que representan cultos antiquísimos, de épocas muy anteriores a la civilización minoica. Son símbolos a veces de difícil interpretación, pero ella se arriesgó a hacer su propia exégesis, en este caso no de un relato mítico, sino de un conjunto de manufacturas de épocas prehistóricas que oscilan entre 6.000 años a. C. (Mesolítico) al último milenio a.C., de lugares dispersos por toda la geografía europea. Su teoría postula el culto a una Gran Diosa madre, común a todos estos pueblos desde los albores de la humanidad, que pervivieron y evolucionaron a formas más complejas según los lugares. Y se dedica a interpretar todos estos dibujos y representaciones de diversos animales, como atributos representativos de esta divinidad primordial.

Cuando empecé la redacción de este artículo, mi intención no iba más allá de comentar este proceso de pérdida del poder y desvalorización de la mujer 
que vemos claramente reflejado en los relatos mitológicos y en los cambios sufridos en los oráculos de Delfos y Dodona. Y podríamos continuar este análisis aplicado a multitud de lugares de culto de la geografía helénica. Pero no puedo ir más allá de estas pinceladas, que por otra parte me han conducido a un hallazgo interesante. Para documentarme más sobre Delfos empecé a leer los Diálogos Píticos de Plutarco (s. II d.C.), ya que descubrí que él mismo había sido sacerdote del templo oracular. Y me topé con que Plutarco aplica la exégesis no sólo al mito y a los dioses, sino también al culto y a los objetos de culto. En concreto tiene uno dedicado a la «E» de Delfos, en la que a la manera de los diálogos platónicos, varios personajes dan su propia interpretación sobre la «E», que se trataba de una ofrenda o exvoto que se le hacía a Apolo en el templo. Junto a las célebres máximas «Conócete a ti mismo» y «Nada en exceso» que presidían la entrada al templo, se encontraba esta misteriosa «E», que probablemente por su antigüedad, ni los propios griegos eran capaces de entender su significado:

Pues bien, nuestro amado Apolo parece ser que, así como los problemas de la vida los remedia y resuelve respondiendo oráculos a quienes le consultan, los del espíritu, en cambio, él mismo los inspira y propone al que es por naturaleza amante del saber, infundiéndole en su alma un impulso que arrastra en pos de la verdad, según es evidente, entre otras muchas pruebas, por la consagración de la E. Es lógico, en efecto, que no haya sido el azar ni por una especie de sorteo por lo que esta sola entre las letras ha llegado a ocupar un lugar preferente junto al dios y ha obtenido el rango de un sagrado exvoto y objeto digno de contemplación, sino que, ya sea en atención a una propiedad suya peculiar y extraordinaria, ya sea porque la utilizaron como símbolo de alguna otra cosa digna de consideración, los que en un principio han investigado sobre el dios, así lo han dispuesto ${ }^{13}$.

Las interpretaciones de los que le acompañan comienza con la de Lamprias, el cual cree que la presencia de la E se debe al hecho de que los famosos siete sabios a los que se atribuyen las dos máximas que allí figuran, eran cinco en realidad (el número 5 se representaba mediante la letra $E$ ), ya que hay dos que se hicieron considerar dentro del grupo de los sabios a través de presiones e influencias, pero que en realidad no lo fueron. Nicandro opina que la E corresponde al inicio de la palabra «si» (en gr. ei), ya que los consultantes siempre preguntan «si van a obtener...», «si se van a casar...»; o que también podría corresponder al inicio de la palabra «ojalá» (en gr. eithe); el propio Plutarco (siguiendo a Éustrofo) intenta justificar la E por su valor como

13. Plutarco. Obras morales y de costumbres (Moralia)VI, p. 240. Biblioteca clásica Gredos, 1995.

Feminismo/s 20, diciembre 2012, pp. 127-142 
número cinco, ya que este es un número perfecto, que encierra en sí mismo el principio femenino (par) y el masculino (impar). Y por último, Amonio la interpreta como una máxima más, que debe ser leída como «tú eres» (ei), algo así como un saludo de los fieles al dios.

Todas estas disquisiciones y esfuerzos de Plutarco por justificar la E, no han convencido a todos, y desde 1901 a 1976, diversos autores como Roscher, Lagerkrantz, Harrison, Bates, Fries, Demangel y Guarducci han aportado nuevas interpretaciones. No he tenido ocasión de acceder a estas fuentes de forma di-

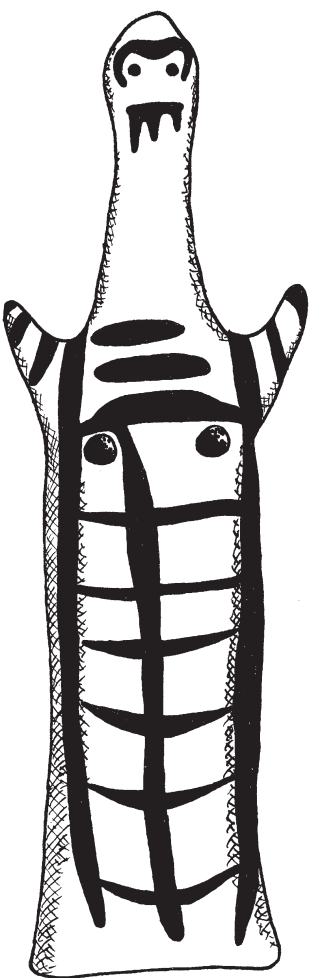

Imagen $n^{\circ} 1$ : Diosa con boca de triple línea, figurilla micénica con la triple línea conectada en la boca, brazos en forma de alas y cabeza de con forma de serpiente. Hallada en Micenas, Peloponeso: c. 1300 a. C. (reproducción en tinta de Clara Bellosta Calvo) recta, sino a través de lo recogido por F. Pordomingo Pardo y J.A. Fernández Delgado, autores de los comentarios a la obra de Plutarco. Entre las propuestas de estos autores hay una que se aproxima a mi interpretación, la de W.N. Bates (1925) que intenta demostrar su origen de carácter minoico que representaba a la Gran Diosa y habría sido transferido de Creta a Delfos (como el propio culto a Apolo pítico), donde, al no ser comprendido, acabó por ser asociado al dios.

Mi nueva exégesis sería algo inconcebible para mi querido Plutarco: yo no veo como él ni un cinco, ni un «si», ni un «ojalá». Casi dos milenios me separan de él y sin embargo creo que ahora tenemos una perspectiva mayor de aquel mundo que les antecedió y que ellos no pudieron vislumbrar, ni siquiera en los vestigios que aún conservaban vivos como esta enigmática «E». Creo, como Bates, que representaba a la Gran Diosa, y podría haber sido transferido desde Creta, aunque no necesariamente, ya que este símbolo esta atestiguado en el mundo minoico y en el Neolítico europeo. Gracias a los símbolos recogidos por Marija Gimbutas, he identificado esta «E» de Delfos con lo que ella llama «triple linea», asociada al agua, a formas serpentinas y a la boca de la Diosa.

En el conocido Disco de Festos, en el que aparecen unos ideogramas escritos en espiral a ambos lados de un pequeño disco de arcilla, 
existe un ideograma identificado como el «peine» ${ }^{14}$, el cual según dispongamos su orientación también se asemejará totalmente a la famosa «E». Según los diversos autores que han estudiado la simbología de estos ideogramas, está ampliamente aceptada esta interpretación. Se le llama «peine, peine de tejer y rastrillo». Es decir, que en cualquiera de las tres acepciones tiene connotaciones femeninas: la que se arregla el cabello, la tejedora y la agricultora. Y en el caso del tejido y del pelo, el número 3 juega un papel importante, en ambos casos se «trenza» (lat. trena, «triple»).

Quizá en las primeras representaciones más antiguas se asociara con el agua, pero en esta forma más

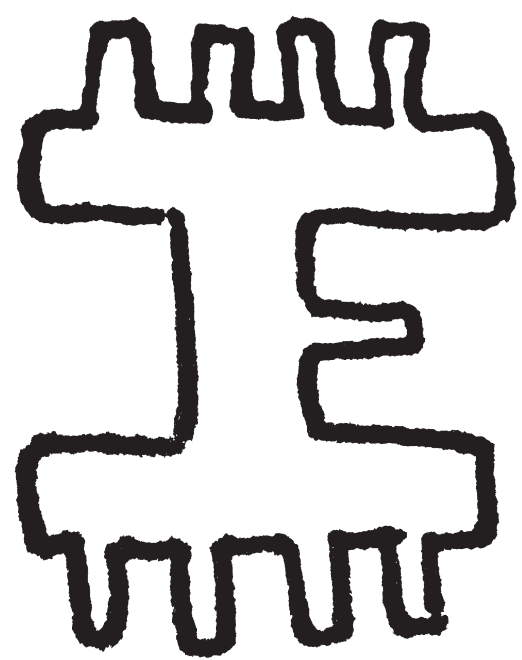

Imagen $n^{\circ}$ 2: E en el disco de Festos, ideograma del disco de Festos(Creta) con forma de «peine» y de E. (reproducción en tinta de Clara Bellosta Calvo). elaborada ya parece representar un instrumento de uso cotidiano, pero que no deja de ser de origen divino: tres son también las tejedoras del destino, las tres Moiras ${ }^{15}$. Representadas en diversas tríadas femeninas en la mitología griega y no griega: las tres Grayas, las tres Parcas, las tres Promántides, las tres Horas, las tres Nonas, las tres Gracias. O como múltiplo de tres: las nueve Musas. La diosa Hécate, de origen oscuro y que se suele asociar con Apolo y Artemis, es una diosa benéfica que otorga la prosperidad material a los hombres (con el ganado, con la pesca, en las batallas y en los juegos), así como la elocuencia en las asambleas políticas. Es una diosa nutricia. Y se le representa en forma de mujer de triple cuerpo o bien tricéfala. En épocas posteriores su papel se especializó como ligada a la magia, se le aparece a los magos y brujas con una antorcha en la mano o con forma de yegua, perra, loba, etc.

14. Balistier, T., The Phaistos Disk. An Acccount of its Unsolved Mystery. Ed. Mähringen, 2000 , p. 51.

15. En el templo de Apolo sólo se hallaban las estatuas de dos de las Moiras, hecho del que tampoco comprendían la razón. A mí me parece evidente: la propia Pitonisa representa a la Moira que falta. 


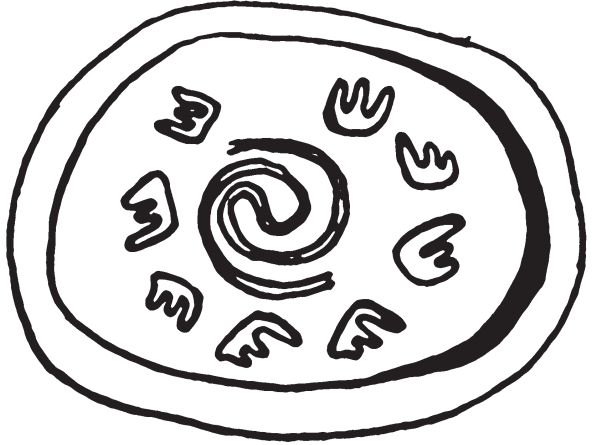

Imagen $n^{\circ}$ 3: Sello de marfil cilíndrico, procedente de un monumento funerario tipo tholos. Vorou, Meseta Mesara, S. de Creta; c. 2000 a. C. (reproducción en tinta de Clara Bellosta Calvo)

Tanto en el caso de la triple Hécate como en el de las Moiras, el número 3 está asociado a los tres momentos de la vida de los humanos: el nacimiento, la vida y la muerte; o dicho de otro modo: el pasado, el presente y el futuro. Y en la exégesis de Plutarco, hablando de la capacidad adivinatoria de Apolo, justifica que la adivinación es el arte de ligar entre sí y enlazar ( o trenzar?) de acuerdo con las leyes de la naturaleza las causas de un todo ${ }^{16}$, y repite las palabras de Homero dichas del adivino Calcante, que conoce y predice «lo que es, lo que será y lo que ha sido».

Otra E asociada a formas serpentinas hallada en un sello minoico:

El peine que desenreda los hilos de la realidad, el peine que ayuda a la tejedora a apretar los hilos en el tapiz, el peine de la Diosa.

En otro de los diálogos de Plutarco, aparece la preocupación sobre por qué antiguamente las Pitias o Pitonisas daban las respuestas en verso y ahora ya no, cosa que se justifica de la siguiente manera:

[...] así que es imposible que hable en forma poética el iletrado que nunca ha escuchado versos. Lo mismo que la que actualmente sirve al dios es hija legítima y honorable como el que más aquí y ha llevado una vida completamente ordenada, pero, criada en una casa de campesinos pobres, desciende a la sede oracular sin llevar consigo nada ni de arte ni de ninguna otra experiencia o habilidad, sino que, lo mismo que Jenofonte cree que la doncella debe ir a casa del varón habiendo visto lo menos posible y oído lo menos posible, así de inexperta e ignorante prácticamente de todo, y virgen en verdad de alma está junto al dios ${ }^{17}$.

Vemos pues la lamentable progresión de sometimiento sobre las mujeres que se produce a rastras del cambio religioso del patriarcado. Aún después de la usurpación del oráculo por la divinidad masculina, que se supone que es la que envía la respuesta, siempre se ha mantenido como transmisoras a las mujeres. Pero se reconoce en estos pequeños cambios, las graves mutilaciones

16. Teoría de los estoicos de la «simpatia universal», sobre la que se apoya la adivinación. 17. Plutarco. Op. cit., p. 326. 
que va sufriendo el género femenino. Si las primitivas Pitias daban los oráculos en verso, está claro que era porque estudiaban. No es casualidad que el monte Parnaso estuviera habitado por las Musas, las que fueran jueces en las competiciones poéticas como la mítica entre Citerón y Helicón. Estas leyendas nos traen vestigios de una sociedad en la que la mujer todavía participaba activamente de la vida intelectual y creativa. Apolo se convierte en el Musageta, «el que dirige a las Musas». Apolo que persigue a Dafne, que horrorizada se convierte en árbol del laurel, con el que luego el dios se corona. Apolo, que persigue a Castalia y se lanza a la fuente que lleva su nombre. Y de una forma parecida a lo que veíamos con Zeus, se apodera de los atributos artísticos de las divinidades femeninas a las que somete: dios de la música y la danza, de la poesía cantada con el acompañamiento de

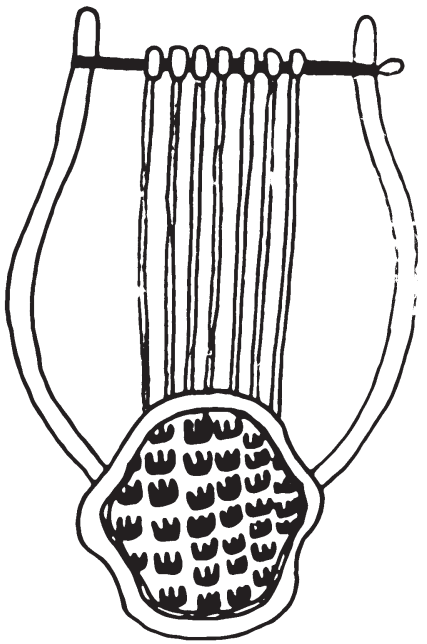

Imagen $n^{\circ} 4$ : detalle de la cítara de Apolo, tomado de la Kylix blanca de Apolo ofreciendo una libación, perteneciente al Museo de Delfos. (Dibujo de Clara Bellosta Calvo) su cítara. Y junto a él se venera también en Delfos otra divinidad masculina con rasgos muy femeninos: Dioniso.

Precisamente en la cítara de Apolo volvemos a ver representada la E de Delfos con idéntica forma a la que veíamos en el sello cretense (Fig. $n^{\circ} 3$ ).

Las referencias al «peine» de la Diosa, siguen apareciendo en multitud de narraciones populares de otras culturas. La casualidad o quizá esa especie de «simpatía universal» o sincronicidad, me ha traído a las manos este pequeño relato irlandés que me dejó sorprendida, y que aporto a modo de despedida. Se llama «El barco de las hadas».

Dice una narración irlandesa que una muchacha, hija de pescadores, cayó al agua y fue recogida en el barco fantasma de las hadas. Años después volvió a visitar a su familia: Su belleza era maravillosa, sus cabellos de oro..., su traje parecía hecho de la espuma de las olas... La muchacha contó cómo vivía: «...Una isla cuajada de palacios y jardines espléndidos, en donde habitan las hadas. Estoy casada con su rey y, aunque me han hecho como ellas, no han podido despojarme de mi corazón humano...» Cinco años más tarde vuelve a visitarles en una pequeña lancha hecha de un rayo de luna, y se va en ella. Pasaron los años. La muchacha regresaba de cuando en cuando. Murió su padre y no tardó en morir su madre...Sus hermanos se repartieron por el mundo...El más pequeño quedó en la casa y se hizo pescador. Se casó, tuvo hijos, 


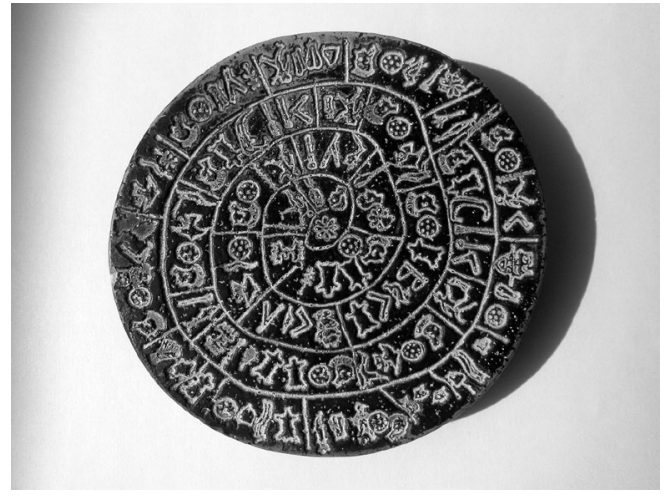

Imagen $n^{\circ}$ 5: Disco de Festos, Creta. Ideogramas en forma de serpiente, desde la cabeza en el centro, la E ocupa el $5^{\circ}$ lugar. (Fotografia de reproducción)
crecieron...Algunas veces los nietos hablaban de su tía el hada, pero sin creer apenas en ella. Una noche... se presentó tan bella y llena de magnificencia como siempre...Pidió un vestido viejo y que le peinaran el cabello con el peine de su madre $y$, a medida que se lo peinaban, se hacía más pequeña y se encogía, se llenaba de arrugas y su pelo se volvía blanco, y se puso tan débil, tan débil... Poco después murió ${ }^{18}$.

\section{Referencias Bibliográficas:}

AAVV., Historia Universal. Los orígenes, Salvat Editores, Barcelona, 2004.

BAilly, A., Dictionnaire Grec-Français, Ed. Hachette, París, 1950.

BAlistier, T., The Phaistos Disk. An Acccount of its Unsolved Mystery, Ed. Mähringen, 2000.

Chantraine, Pierre, Dictionnaire Etymologique de la Langue Grecque. Histoire des mots, Editions Klincksiek, Paris, 1980.

GIL, Rodolfo, Los cuentos de hadas: historia mágica del hombre, Aula Abierta Salvat, Barcelona, 1982.

GIMBUTAS, Marija, El lenguaje de la diosa, Grupo Editorial Asturiano GEA, Oviedo, 1996.

GRIMAL, Pierre, Diccionario de Mitología griega y romana, Paidós, Barcelona, 1986.

MAdrid, Mercedes. La misoginia en Grecia, Ed. Cátedra/U. de Valencia, Madrid, 1999.

Petracos, Basilio, Delfos, Ediciones Clio, Atenas, 1997.

-, Museo Nazionale. Sculture-Bronze-Vasi, Ed. Clio, Atenas, 1993.

PlutarCo, Obras morales y de costumbres (Moralia) VI, Gredos, Madrid, 1995.

SAlEllarakis, J.A., Herakleion Museum. Illustrated Guide, Ekdotike Athenon, Atenas, 2000.

18. GiL, Rodolfo. Los cuentos de hadas: historia mágica del hombre, Aula Abierta Salvat, Barcelona, 1982. 